\title{
Pembangunan Instalasi Cuci Tangan dalam Menurunkan Risiko Penyebaran Covid-19 di TPA Km. 14 Kota Palangka Raya
}

\author{
Construction of Handwashing Installations to Reduce the Risk of Covid-19 Spreads in Km. 14 \\ Landfill Palangka Raya City
}

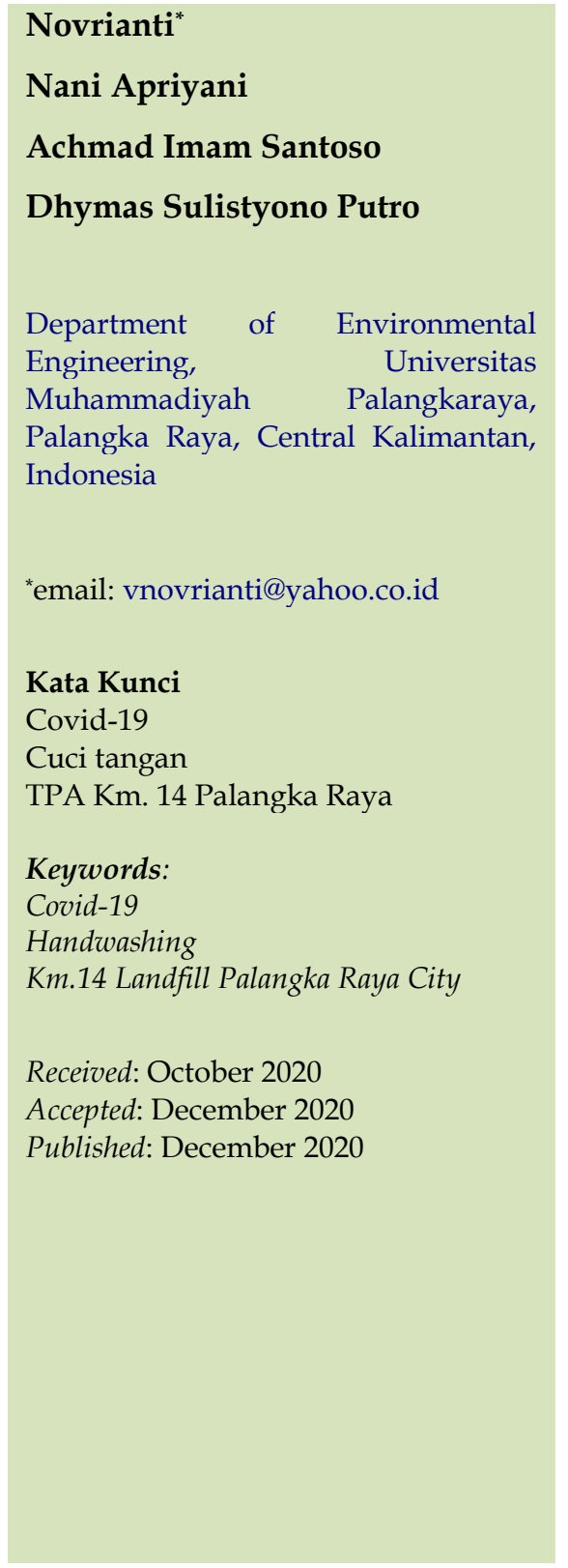

\begin{abstract}
Abstrak
Pemulung memiliki risiko tertular Covid-19 yang berasal dari sampah saat dipilah. Berdasarkan hal tersebut, perlu dilakukan upaya pembangunan instalasi cuci tangan di lingkungan TPA Km.14 Palangkaraya sebagai upaya untuk pencegahan Covid-19, untuk kenyamanan Pemulung dalam bekerja tanpa perlu adanya kekhawatiran. Penempatan instalasi cuci tangan didasari pada titik yang sering dilalui oleh pemulung, sehingga akan lebih mudah untuk diakses. Mudahnya akses tersebut, akan meningkatkan penggunaan instalasi cuci tangan, yang akan berpotensi menurunnya risiko penyebaran Covid-19 di TPA Km. 14 Palangkaraya. Tandon 250 L diletakkan diatas penyangga kayu. Peletakkan tersebut bertujuan untuk memudahkan pemasangan kran air serta saat mencuci tangan. Pemasangan kran air dilakukan pada lubang tandon $250 \mathrm{~L}$ yang disediakan oleh pihak produksi tandon $250 \mathrm{~L}$. Wastafel ditempatkan tepat dibawah luaran kran air, sehingga memudahkan saat mencuci tangan dan mengatur aliran air. Aliran air hasil cuci tangan yang tertampung, selanjutnya akan mengalir secara gravitasi menuju penyaring air yang telah terpasang pada selang untuk selanjutnya dilakukan penyaringan ,sehingga saat mengalir ke tanah air hasil cuci tangan tidak menurunkan kualitas tanah maupun air tanah.
\end{abstract}

\begin{abstract}
Scavengers have a risk of contracting Covid-19, which comes from the garbage when it is sorted. Based on this, it is necessary to make efforts to build a handwashing installation in the Km. 14 Landfill Palangka Raya City environment to prevent Covid-19, for the convenience of scavengers at work without the need for worries. The handwashing installation placement is based on the points that scavengers frequently pass so that it will be easier to access. This easy access will increase handwashing installations, which will potentially reduce the risk of Covid-19 spreads in the Km. 14 Landfill Palangka Raya City. The $250 \mathrm{~L}$ reservoir is placed on a wooden support. The placement is intended to facilitate the installation of water taps and when washing hands. The installation of water faucets is carried out in the $250 \mathrm{~L}$ reservoir provided by the $250 \mathrm{~L}$ reservoir producer. The sink is placed just below the water faucet outside, making it easier to wash hands and regulate water flow. The water flow from the collected hand washing will then flow gravitationally to the water filter that has been attached to the hose for further filtering so that when it flows into the country, the results of handwashing will not reduce the quality of the soil or groundwater.
\end{abstract}

(C) 2020 Novrianti, Nani Apriyani, Achmad Imam Santoso, Dhymas Sulistyono Putro. Published by Institute for Research and Community Services Universitas Muhammadiyah Palangkaraya. This is Open Access article under the CC-BY-SA License (http://creativecommons.org/licenses/by-sa/4.0/). DOI: https:// doi.org/10.33084/pengabdianmu.v6i1.1860

\section{PENDAHULUAN}

Kondisi TPA Km 14 Palangkaraya merupakan tempat pembuangan sampah akhir di Kota Palangkaraya yang setiap harinya sampah masuk lebih dari 10 Ton (Permana \& Trihadiningrum, 2010). Salah satu pihak yang terlibat dalam menunjang operasional TPA Km 14 
Palangkaraya yaitu pemulung. Pemulung berpotensi mengurangi timbunan sampah di TPA dengan memilah sampah yang masih memiliki nilai ekonomi dengan dijual kembali untuk didaur ulang (Hariyani et al., 2013; Zulianti, 2017; Moerad, 2012). Sampah yang dipilah akan berpotensi mengganggu kesehatan saat kontak langsung dengan tubuh pemulung (Seppina et al., 2017). Hal ini didukung dengan adanya pandemi Covid-19 yang berpotensi berada pada sampah yang akan dipilah oleh pemulung. Dengan demikian, pemulung akan memiliki risiko tertular Covid-19 yang berasal dari sampah saat dipilah.

Upaya penurunan risiko pemulung terkena Covid-19 atau sebagai penyebar dapat dilakukan dengan Penerapan Hidup Bersih dan Sehat (PHBS) seperti mencuci tangan menggunakan sabun. Penggunaan sabun akan menurunkan mikroorganisme yang berada pada tangan, tidak menutup kemungkinan Covid-19 (Fazlisia et al., 2014). Sehingga, mencuci tangan menggunakan sabun saat sebelum maupun setelah memilah sampah akan menurunkan potensi penularan Covid-19 yang berasal dari sampah. Minimnya instalasi cuci tangan di lingkungan TPA Km.14 Palangkaraya menyebabkan pemulung tidak dapat mencuci tangan saat sebelum dan setelah memilah sampah, sehingga berpotensi meningkatkan penyebaran Covid-19. Adanya instalasi cuci tangan di lingkungan TPA Km.14 Palangkaraya maka pemulung dapat mencuci tangan dengan sabun sebelum dan setelah memilah sampah, sehingga akan berpotensi menurunkan penyebaran Covid-19.

\section{METODOLOGI}

Kegiatan ini dimulai dengan berkoordinasi dan perizinan kepada pengelola TPA Km. 14 Palangkaraya. Setelah perizinan selesai, tim akan berkoordinasi untuk menyiapkan sarana dan prasarana untuk menunjang pelaksanaan berjalan maksimal. Selain menyiapkan instalasi maupun bahan yang akan digunakan dalam pembangunan instalasi cuci tangan, seperti penentuan lokasi, tandon 250 L sebagai penampung air, kayu penahan sebagai dudukan tandon $250 \mathrm{~L}$, selang untuk menunjang distribusi air, kran air sebagai pengatur keluaran air dari tandon $250 \mathrm{~L}$, wastafel sebagai penampung sementara air hasil cuci tangan, serta penyaring air berfungsi meningkatkan kualitas air hasil cuci tangan agar menjaga kualitas tanah sebagai muara outlet air hasil cuci tangan.

\section{HASIL DAN PEMBAHASAN}

Adanya instalasi cuci tangan akan menurunkan tingkat penyebaran Covid-19 di lingkungan TPA Km. 14 Palangkaraya, sehingga akan menurunkan risiko pemulung di lingkungan TPA Km. 14 Palangkaraya terjangkit Covid-19 (Telaumbanua, 2020). Selain mampu menurunkan risiko penyebaran Covid-19, keberadaan instalasi cuci tangan mampu menurunkan penyebaran penyakit yang diakibatkan oleh kontak benda terhadap tangan. Sehingga, keberadaan instalasi cuci tangan di TPA Km. 14 Palangkaraya sangat diperlukan (Sumarni, 2012). Pada instalasi cuci tangan ini, air dibedakan menjadi dua yaitu air bersih sebagai bahan baku mencuci tangan serta air hasil cuci tangan merupakan air yang telah digunakan dalam mencuci tangan dan tercampur dengan sabun tangan (Artayana \& Atmaja, 2010).

Penempatan instalasi cuci tangan didasari pada titik yang sering dilalui oleh pemulung, sehingga akan lebih mudah untuk diakses. Mudahnya akses tersebut, akan meningkatkan penggunaan instalasi cuci tangan, yang akan berpotensi menurunnya risiko penyebaran Covid19 di TPA Km. 14 Palangkaraya (Nakoe et al., 2020). Sumber air bersih berasal dari air PDAM yang telah dialirkan sebelumnya ke TPA Km. 14 Palangkaraya, sehingga secara kualitas dan kuantitas air telah terjaga 
secara optimal. Lokasi penempatan instalasi dan sumber air telah ditentukan, tandon $250 \mathrm{~L}$ diletakkan diatas penyangga kayu. Peletakkan tersebut bertujuan untuk memudahkan pemasangan kran air serta saat mencuci tangan. Pemasangan kran air dilakukan pada lubang tandon $250 \mathrm{~L}$ yang disediakan oleh pihak produksi tandon 250 L. Wastafel ditempatkan tepat dibawah luaran kran air, sehingga memudahkan saat mencuci tangan dan mengatur aliran air. Aliran air hasil cuci tangan yang tertampung, selanjutnya akan mengalir secara gravitasi menuju penyaring air yang telah terpasang pada selang untuk selanjutnya dilakukan penyaringan ,sehingga saat mengalir ke tanah air hasil cuci tangan tidak menurunkan kualitas tanah maupun air tanah. Gambar 1. merupakan instalasi cuci tangan yang telah siap digunakan.

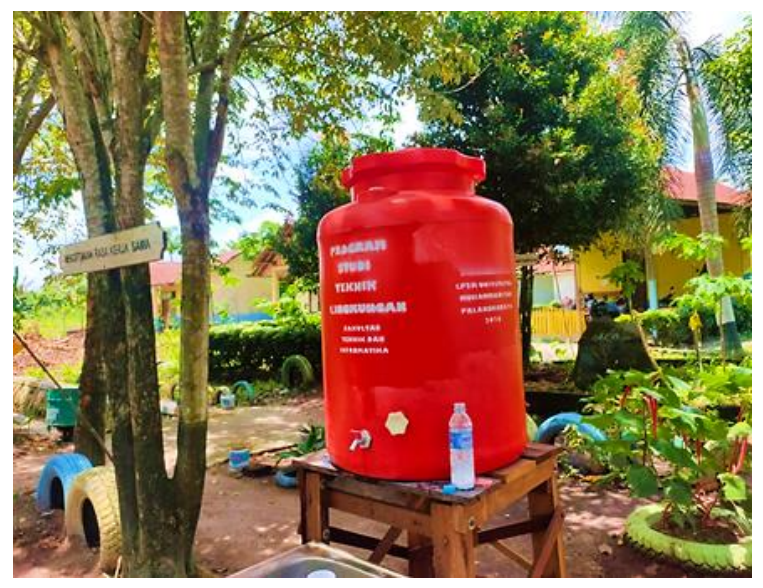

Gambar 1. Instalasi cuci tangan siap pakai

Penyaring air ini terdiri atas beberapa komponen, diantaranya karbon aktif pada Gambar 2 dan kapas pada Gambar 3. Fungsi karbon aktif adalah menyerap senyawa kimia yang terdapat dalam sabun tangan saat larut dalam air. Sedangkan kapas berfungsi sebagai filter partikel-partikel yang penyebab air hasil cuci tangan menjadi keruh. Dengan demikian, air hasil cuci tangan tidak akan menurunkan kualitas tanah maupun air tanah yang menjadi muara air hasil cuci tangan. Gambar 4 merupakan penyaring air yang digunakan.

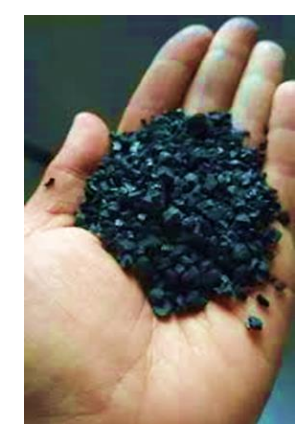

Gambar 2. Karbon aktif

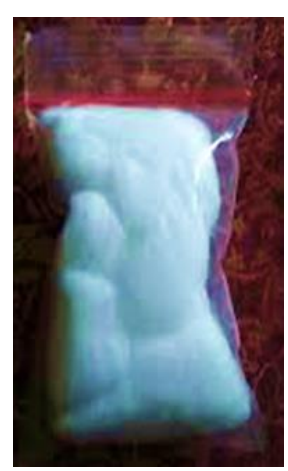

Gambar 3. Kapas

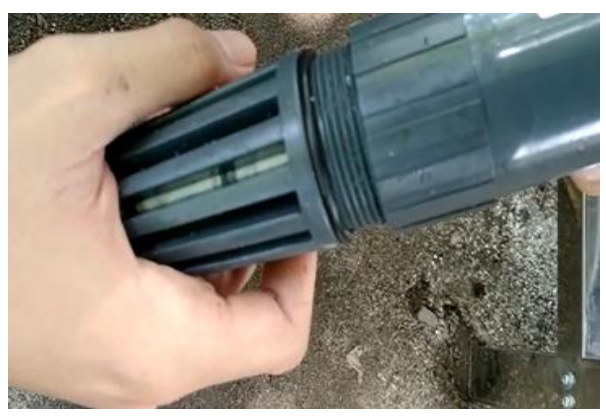

Gambar 4. Penyaring air

Pihak pengelola TPA Km. 14 Palangkaraya menyambut kegiatan ini dengan terbuka, hal ini terlihat dalam memberikan izin kepada tim untuk melaksanakan kegiatan di area TPA Km. 14 Palangkaraya. Selain itu, pengelola TPA Km. 14 Palangkaraya terlibat pula dalam proses pembangunan instalasi cuci tangan, seperti merekomendasikan titik yang sering dilalui oleh pemulung sebagai lokasi penempatan instalasi cuci tangan serta membantu secara fisik saat konstruksi instalasi cuci tangan. Terkait pengelolaan instalasi cuci tangan selenjutnya, sepenuhnya akan dikelola oleh Pihak pengelola TPA Km. 14. Bentuk pengelolaan yang 
dapat dilakukan yaitu pengisian air bersih dan menyediakan sabun cuci tangan.

\section{KESIMPULAN}

Kesimpulan yang didapatkan dalam kegiatan ini diantaranya pembangunan instalasi cuci tangan berpotensi menurunkan risiko penyebaran Covid-19 di lingkungan TPA Km. 14 Palangkaraya dan air hasil cuci tangan tidak berpotensi menurunkan kualitas tanah dan air tanah dikarenakan telah menggunakan teknologi penyaring air yang mampu meningkatkan kualitas air hasil cuci tangan

\section{UCAPAN TERIMA KASIH}

Kami sebagai tim penyusun mengucapkan terima kasih kepada LP2M Universitas Muhammadiyah Palangkaraya yang telah memberikan dukungan dana melalui Surat Keputusan Rektor Universitas Muhammadiyah Palangkaraya No. 50/PTM63.R/SK/N/2020 tentang Penetapan Proposal yang Mendapatkan Bantuan Biaya Pengabdian Masyarakat Universitas Muhammadiyah Palangkaraya Tahun Anggaran 2020 serta pihak pengelola TPA Km. 14 Palangkaraya yang telah memberikan izin kepada tim serta membantu secara teknis pelaksanaan kegiatan.

\section{REFERENSI}

Artayana, K.C.B., Atmaja, G.I. 2010. Perencanaan Instalasi Air Bersih dan Air Kotor Pada Bangunan Gedung dengan Menggunakan Sistem Pompa. Jurnal Energi dan Manufaktur. 4(1):51-56.

Fazlisia, A., Bahar, E., Yulistini, Y. 2014. Uji Daya Hambat Sabun Cair Cuci Tangan pada Restoran Waralaba di Kota Padang Terhadap Pertumbuhan Bakteri Escherichia coli dan Staphylococcus aureus Secara In Vitro. Jurnal Kesehatan Andalas. 3(3):348-353. https://doi.org/10.25077/jka.v3i3.116
Hariyani, N., Prasetyo, H., Soemarno, S. 2013. Partisipasi Pemulung Dalam Pengelolaan Sampah Di TPA Supit Urang Mulyorejo Sukun Kota Malang. Jurnal Pembangunan dan Alam Lestari (J-PAL). 4(1):11-17.

Moerad, S.K. 2012. Peran Serta Masyarakat Pemulung dalam Pengelolaan Lingkungan Binaan Di TPA Benowo Surabaya. NUANSA: Jurnal Penelitian Ilmu Sosial dan Keagamaan Islam. 9(2):235-250.

http://dx.doi.org/10.19105/nuansa.v9i2.153

Nakoe, R., Lalu, N.A.S., Mohamad, Y.A. 2020. Perbedaan Efektivitas Hand-Sanitizer Dengan Cuci Tangan Menggunakan Sabun Sebagai Bentuk Pencegahan Covid-19. Jambura Journal of Health Sciences and Research. 2(2):65-70. https://doi.org/10.35971/jhhsr.v2i2.6563

Permana, T.J., Trihadiningrum, Y. 2010. Kajian Pengadaan Dan Penerapan Tempat Pengolahan Sampah Terpadu (TPST) di TPA km.14 Kota Palangka Raya. In Prosiding Seminar Nasional Manajemen Teknologi XI. Surabaya: Institut Teknologi Sepuluh November.

Seppina, D.S., Hilal, N., Rudijanto, H.I.W. 2017. Upaya Pemulung dalam Mencegah Risiko Gangguan Kesehatan di TPA Banjaran Kecamatan Bojongsari Kabupaten Purbalingga Tahun 2017. $\quad$ LINK. 13(1):15-19. https://doi.org/10.31983/link.v13i1.2589

Sumarni, S. 2012. Sosial Ekonomi Komunitas Pemulung di TPA Lubuk Minturun. Economica: Jurnal Program Studi Pendidikan Ekonomi STKIP PGRI Sumatera Barat. 1(1):159-171. https://doi.org/10.22202/economica.2012.v1 .i1.111

Telaumbanua, D. 2020. Urgensi Pembentukan Aturan Terkait Pencegahan Covid-19 di Indonesia. Qalamuna : Jurnal Pendidikan, Sosial, dan Agama. 12(1):59-70. https://doi.org/10.37680/qalamuna.v12i01.2 90

Zulianti, Z. 2017. Peran Paguyuban Pemulung Wanita Di TPSP Piyungan, Kabupaten Bantul, Daerah Istimewa Yogyakarta. Jurnal NATAPRAJA: Kajian Ilmu Administrasi Negara. 5(2):127-136. https://doi.org/10.21831/jnp.v5i2.18762 